Supporting Information

\title{
Recombinant Spider Silk and Collagen-Based Nerve Guidance Conduits Support Neuronal Cell Differentiation and Functionality in vitro
}

Kiran Pawar, ${ }^{1, \dagger}$ Georg Welzel, ${ }^{2}$ Christian Haynl, ${ }^{1}$ Stefan Schuster $^{2}$ and Thomas Scheibel $1,3,4,5,6,{ }^{*}$

${ }^{1}$ University of Bayreuth, Department for Biomaterials, Prof.-Rüdiger-Bormann-Str.1, 95447

Bayreuth, Germany

${ }^{2}$ University of Bayreuth, Department of Animal Physiology, Universitätsstraße 30, 95447

Bayreuth, Germany

${ }^{3}$ University of Bayreuth, Bayreuther Zentrum für Kolloide und Grenzflächen (BZKG),

Universitätsstraße 30, 95447 Bayreuth, Germany

${ }^{4}$ University of Bayreuth, Bayreuther Zentrum für Molekulare Biowissenschaften (BZMB),

Universitätsstraße 30, 95447 Bayreuth, Germany

${ }^{5}$ University of Bayreuth, Bayreuther Materialzentrum (BayMAT), Universitätsstraße 30, 95447

Bayreuth, Germany

${ }^{6}$ University of Bayreuth, Bayerisches Polymerinstitut (BPI), Universitätsstraße 30, 95447

Bayreuth, Germany

†Present address: University of British Columbia, ICORD, 818 West 10th Avenue, Vancouver, BC Canada V5Z 1M9

*To whom correspondence should be addressed: thomas.scheibel@bm.uni-bayreuth.de 

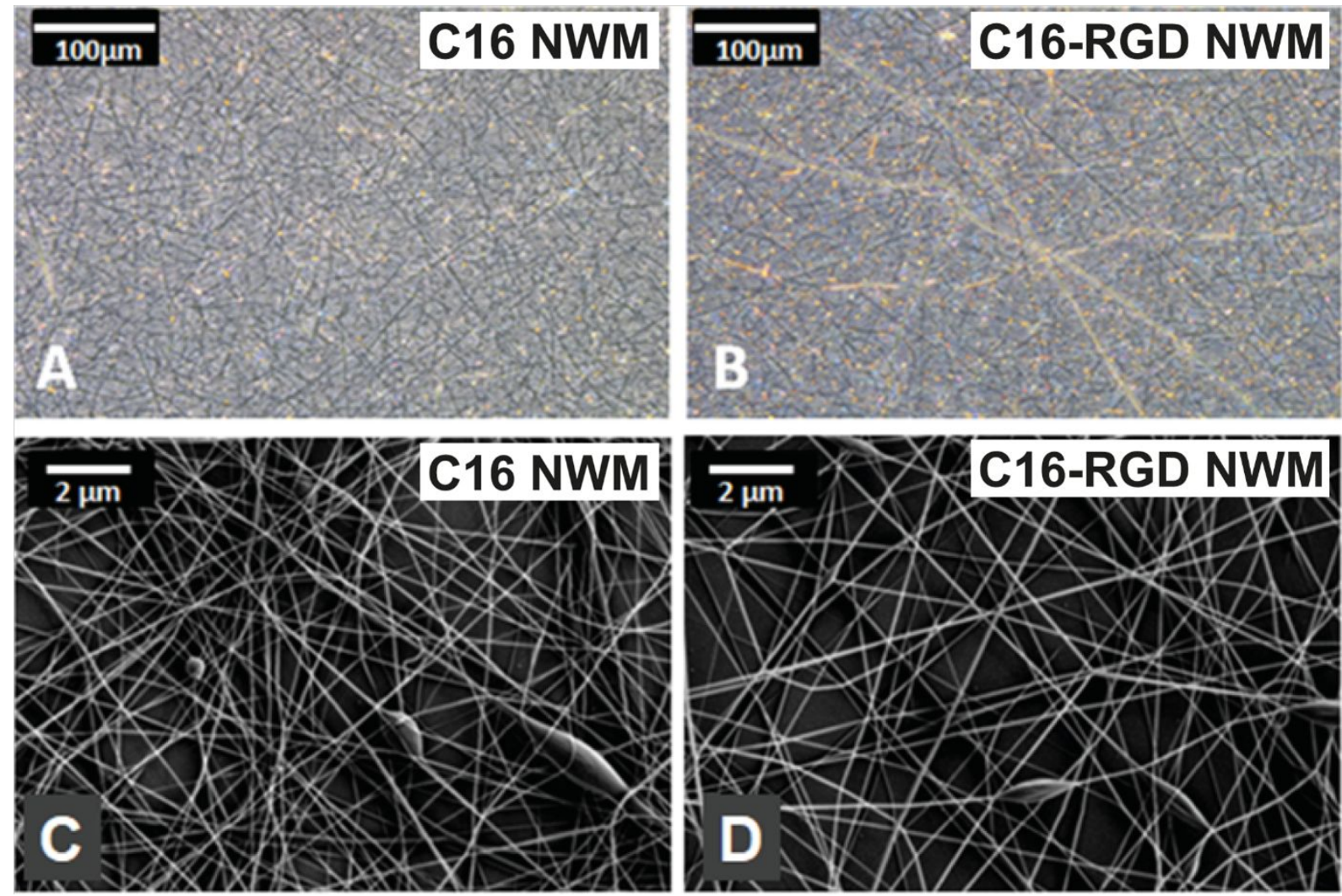

Figure S1. (A, B) Light microscopy images and (C, D) scanning electron microscopy (SEM) images of nonwoven meshes (NWM) collected on glass coverslips. 

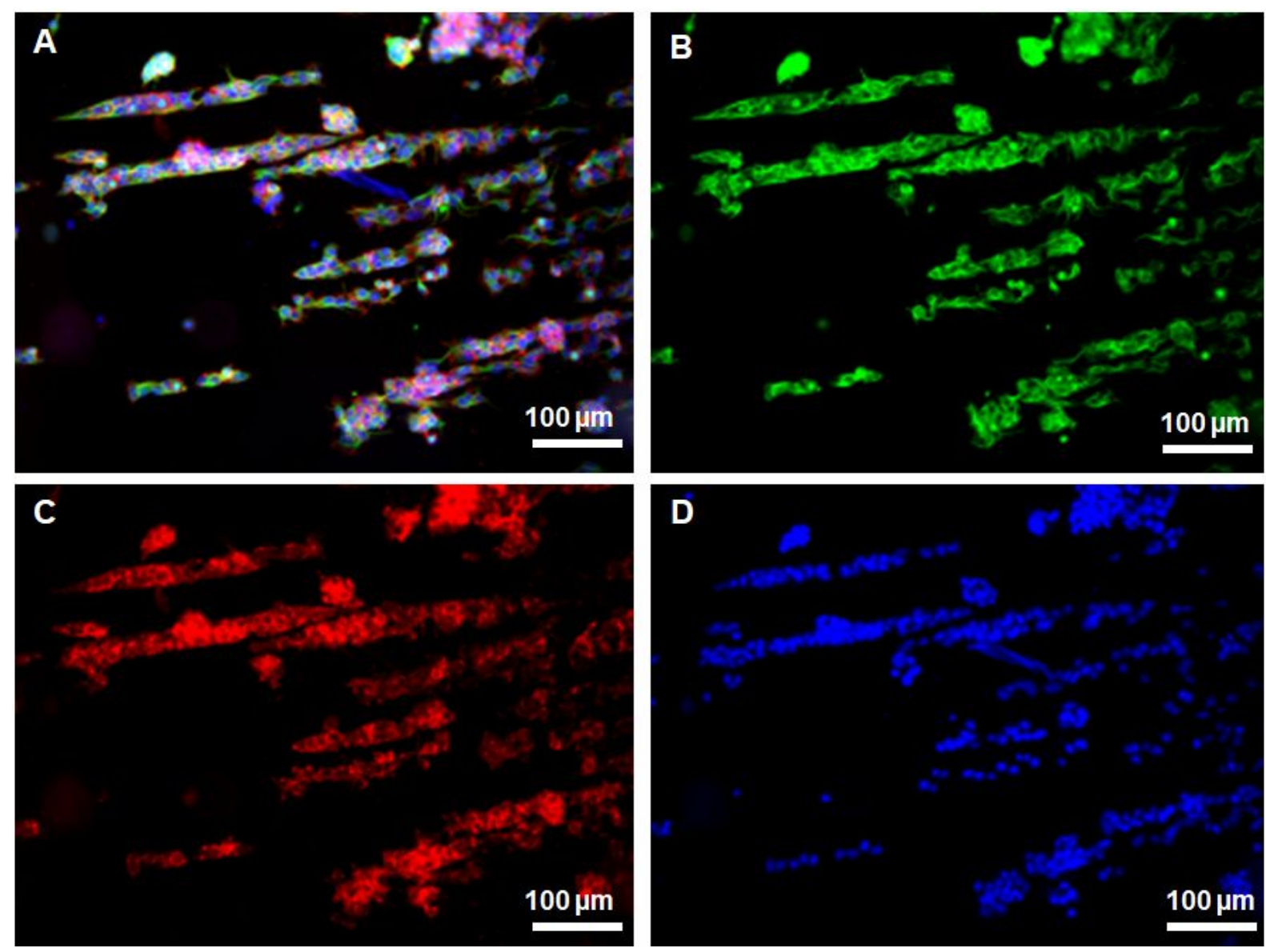

Figure S2: Fluorescence microscopy images of adhered NG108-15 cells on aligned collagen fibers on day 3 of culture. (A) Merge, (B) expression of ß-tubulin III, (C) expression of F-actin and (D) Hoechst staining showing cell nuclei. 


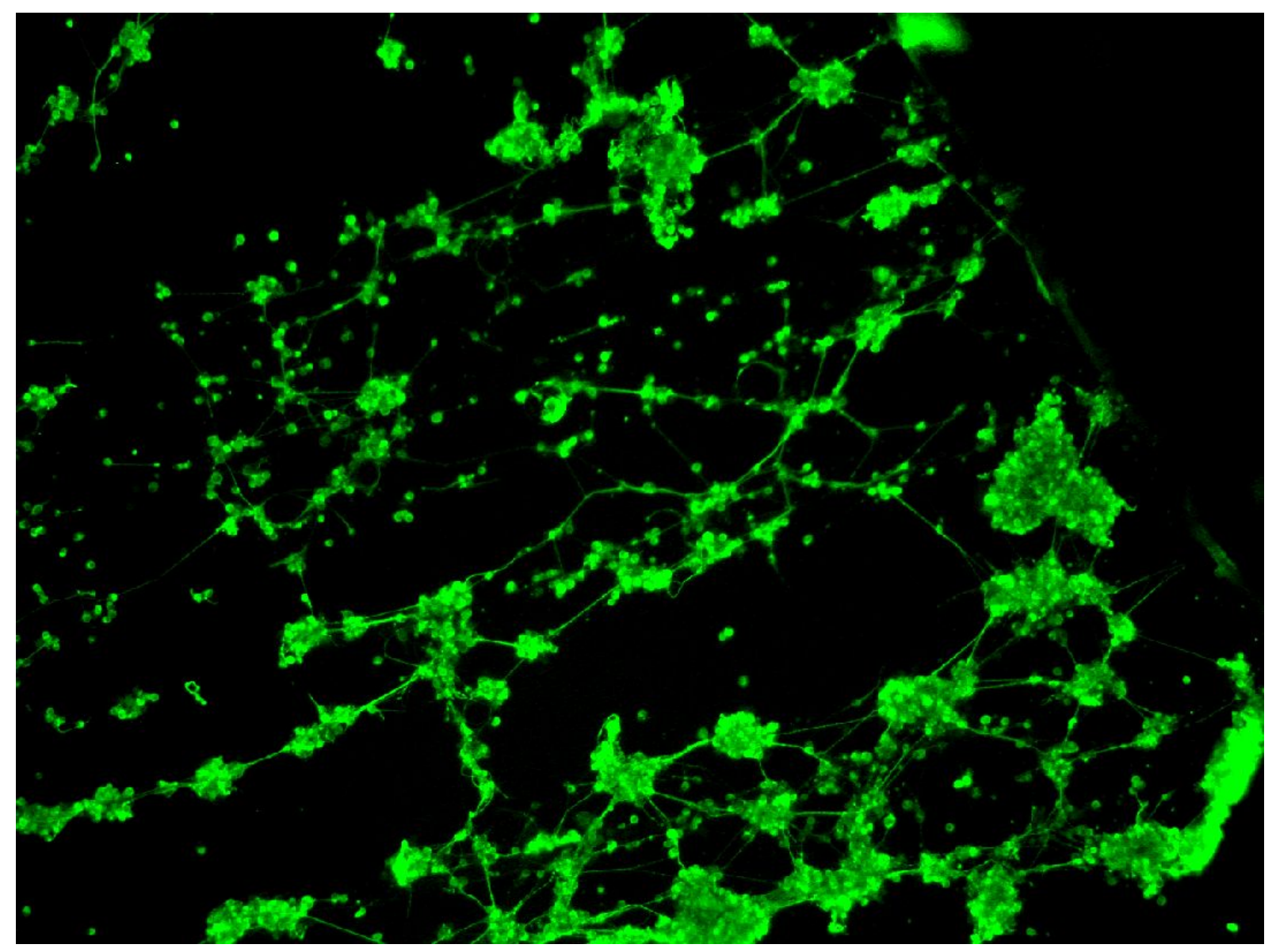

Figure S3: Fluorescence microscopy images of NG108-15 cells on aligned collagen fibers after differentiation on day 3 of culture. Green fluorescence indicates the expression of $\beta$-tubulin III. 

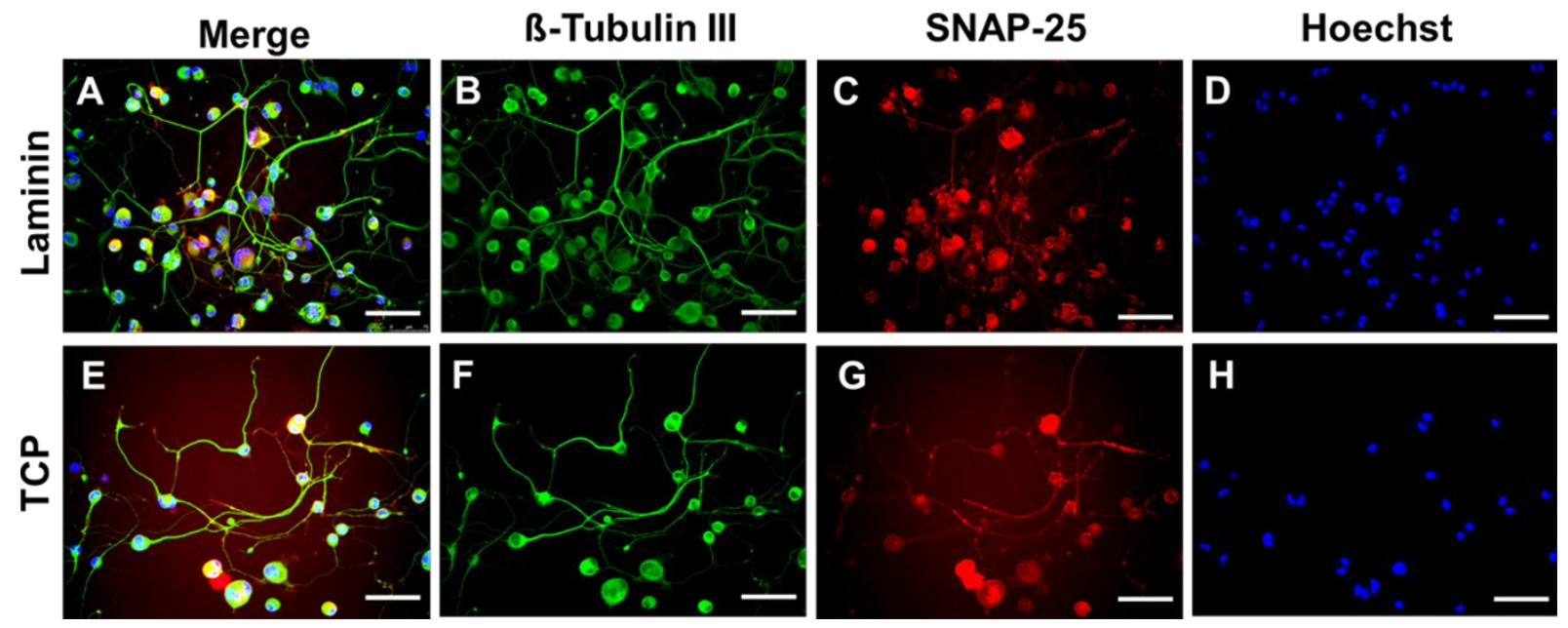

Figure S4. NG108-15 neuronal cell differentiation and synapse formation on a laminin-coated glass coverslip and on a treated tissue culture plate (TCP) after 3 weeks of culturing. Neuronal cells show long neurite growth and neuronal networks on (A) laminin-coated glass and on (E) TCP, both acting as positive controls. (B, F) Differentiated neurons are immunoreactive for $\beta$ tubulin III (green). (C, G) Neuronal networks form synapses and are immunoreactive for SNAP25 (red). (D, H) Neuronal cell nuclei marked with Hoechst (blue). Scale bars: $100 \mu \mathrm{m}$. 
Table S1. Differentiation-induced changes in membrane properties of NG108-15 cells grown on recombinant spider silk nonwoven meshes (NWM) and on collagen fibers. The resting membrane potential, the maximum rate of depolarization and the depolarization amplitude are shown in differentiated NG108-15 cells with $(n=9)$ and without $(n=13)$ the ability to generate action potentials. No significant differences were observed between the two NWM variants and the collagen fibers. All data are presented as mean \pm SD.

\begin{tabular}{cccc}
\hline NG108-15 cells & $\begin{array}{c}\text { Resting membrane } \\
\text { potential }[\mathrm{mV}]\end{array}$ & $\begin{array}{c}\text { Maximum rate of depolarization } \\
{\left[\mathrm{mV} \mathrm{ms}{ }^{-1}\right]}\end{array}$ & $\begin{array}{c}\text { Depolarization } \\
\text { amplitude }[\mathrm{mV}]\end{array}$ \\
\hline - action potentials & $-33.7 \pm 2.1$ & $22.5 \pm 1.2$ & $51.3 \pm 3.5$ \\
+ action potentials & $-41.9 \pm 3.0$ & $49.2 \pm 6.5$ & $87.6 \pm 4.7$ \\
\hline
\end{tabular}
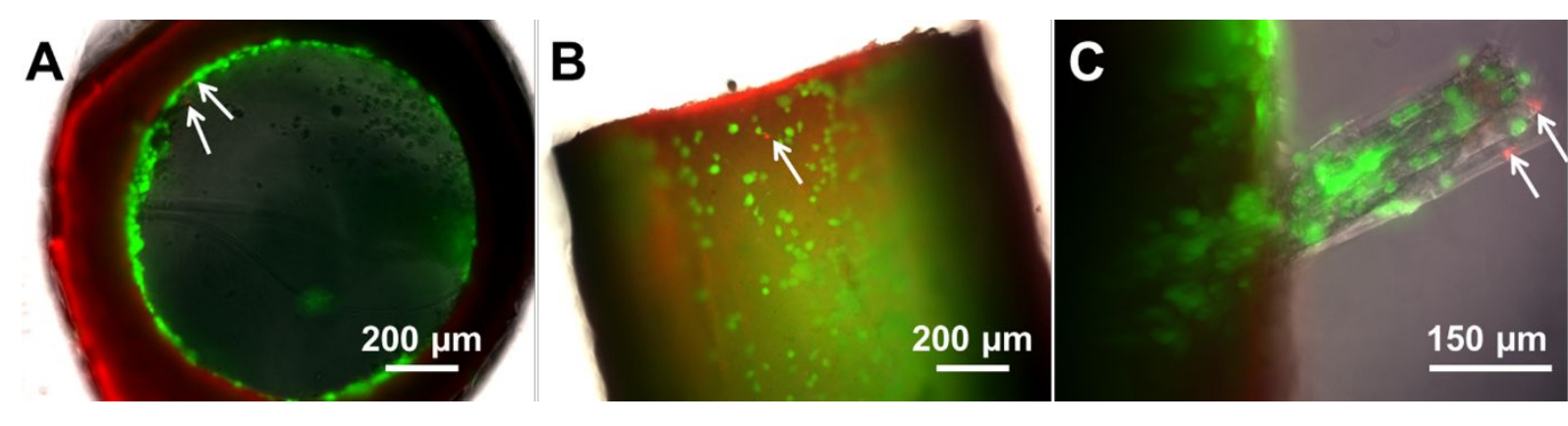

Figure S5. Live dead staining showing NG108-15 cells differentiated in the NGC after 3 days of culturing. (A) Neuronal cells showed an even distribution inside the C16-RGD NWM tube with very few dead cells in red (white arrows). (B) Differentiated live cells with neurites on the inner wall of the tube structure with negligible dead cells in red (white arrow). (C) Differentiated cells on collagen fibers in the tube structure with very few dead cells in red (white arrow). 